\title{
Integration of the Newborn Resuscitation-Training Program in Pediatric Nursing Teaching: A Mixed-Method Study
}

\author{
Haydeh Heidari, ${ }^{1}$ and Marjan Mardani-Hamooleh ${ }^{2,}$ \\ ${ }^{1}$ Department of Nursing, Modeling in Health Research Center, Shahrekord University of Medical Sciences, Shahrekord, IR Iran \\ ${ }^{2}$ Department of Nursing, Iran University of Medical Sciences, Tehran, IR Iran \\ "Corresponding author: Marjan Mardani-Hamooleh, School of Nursing and Midwifery, Iran University of Medical Sciences, Zafar Str, Vanak Sq, PO Box 1419733171, Tehran, IR Iran. \\ Tel: +98-9132864077, Fax: +98-2188201881, E-mail: mardanimarjan@gmail.com
}

Received 2016 September 03; Revised 2016 September 17; Accepted 2016 October 31.

\begin{abstract}
Background: The neonatal care in the first few minutes after birth could affect the newborn's quality of personal life and thus its entire lifetime.

Objectives: The aim of this study was to examine the integration of the newborn resuscitation-training program in pediatric nursing teaching.

Methods: The present study was a mixed-method study, which began with qualitative and quantitative data collection at the same time. That is why the qualitative and quantitative steps performed at the same time. The qualitative phase was conducted based on the qualitative content analysis. Purposeful sampling was performed. Saturation occurred with10 interviews. The quantitative phase was performed based on a researcher-made questionnaire. The content validity of the questionnaire was confirmed by the feedback of experts and its reliability was assessed by Cronbach's alpha 92\%. The number of students at this stage was 48 .

Results: Based on the results of the qualitative phase, two main categories of clinical skills promotion and the necessity of attention to educational needs of students were obtained, which was in accordance with the results of the quantitative step. Based on the results of the quantitative step, the following results were obtained: areas of the resuscitation-training program improved my skills ( $83 \%$ strongly agree and $17 \%$ agree); I am satisfied with resuscitation-training program (94\% strongly agree and 6\% agree); I agree with continuing resuscitation program in future terms (77\% strongly agree, $21 \%$ agree, and $2 \%$ disagree); the resuscitation-training program conformed with students' needs (92\% strongly agree, $4 \%$ agree and $2 \%$ disagree); and the quality of resuscitation training program was appropriate ( $94 \%$ strongly agree and $6 \%$ agree).

Conclusions: Performing the newborn resuscitation for nursing students and increasing their knowledge and skills may lead to increase student motivation, reduce hospital costs and increase the quality of care.
\end{abstract}

Keywords: Resuscitation, Mixed-Method Research, Pediatric Nursing, Students

\section{Background}

Ten percent of infants need help to start breathing. Of this number, 5\% - 10\% need the first steps, 3\% - 5\% need initial resuscitation and $1 \%$ require advanced resuscitation (13). These statistics show that by the newborn resuscitation training, one million infants' lives can be saved each year (4). Therefore, the neonatal care in the first few minutes after birth could affect the newborn's quality of personal life and thus its entire lifetime (5).

More than $98 \%$ of infant deaths occur in low and middle-income countries (6). Newborn resuscitation training programs teach nurses basic skills and concepts of resuscitation (7). Knowledge and skills are necessary for successful resuscitation. Good quality resuscitation is from the key points of resuscitation instructions (8). Group exercise in simulated resuscitations improves performance and potentially improves outcomes (9). Woollard et al. stated that several factors are effective in resus- citation competence, but the most critical factors in resuscitation training are knowledge and skills (10). The results of one study revealed that the authorities should pay more attention to personnel training about newborn resuscitation (11).

Considering that resuscitation training improves the performance of the health care team and since the important task of care in the future is the responsibility of nursing students, if the students learn during the training principles, they will be better prepared for the task (12). Resuscitation training besides increasing students' knowledge and skills can also improve newborn health care services (13). The aim of this study was to examine the integration of the resuscitation-training program in pediatric nursing teaching, in order to take a step toward improving clinical services with their proper training. 


\section{Methods}

The present study was a mixed-method research, which began with qualitative and quantitative data collection at the same time. The study was performed on nursing students who had pediatric nursing in 2015. Ten nursing students in 6th semester were selected using the goalbased approach. First, the resuscitation-training program in nursing students was implemented in theory and practice.

\subsection{Learning Objectives}

After the resuscitation-training program, the students expected to:

1) Express the first steps of resuscitation.

2) Explain the difference between adult and newborn resuscitation.

3) Express initial efforts to apnea caused by meconium aspiration.

4) Explain the difference between the primary and secondary apnea.

5) Illustrate what are the indications for chest compressions.

6) Explain the indications of endotracheal tube.

7) Perform airway suctioning on meconium aspiration.

8) Show endotracheal intubation on meconium aspiration.

9) Explain the necessary arguments regarding the measures that will be performed in the newborn with apnea.

10) Express indications of pharmacotherapy in newborn resuscitation.

The above program was implemented theoretically and practically (in the practice room). Each of the theoretical training program and practical training was conducted in two sessions for groups of 8-10 subjects. The quantitative and qualitative steps were performed simultaneously at the end of the period. Finally, the results of the two steps were integrated.

A) The qualitative step: at the end of the resuscitation training, students' experiences were examined. The qualitative phase was conducted based on the qualitative content analysis (14). The content analysis is inductive, includes open coding, and creates classification and abstraction (15). The location of individual interviews was hospital. The average duration of interviews was $25 \mathrm{~min}$ utes. Interviews started with an open-ended question: "please tell us from your experiences about the newborn resuscitation-training program". The interview continued with detailed questions. Sampling and data collection continued until the data saturation was occurred. Saturation occurred with10 interviews. After listening to the tape several times, the researcher obtained the data from the interviewers. The content analysis of the raw data included open coding for categorizing and abstracting the data and using a seven-stage process as follows: 1) obtaining information regarding the research question, 2) sampling for analysis, 3) describing the relevant categories, 4) determining the coding process and training the coder, 5) implementing the coding process, 6 ) determining the trustworthiness of the research process, and 7) analyzing the results of the coded data (15). All interviews were transcribed word by word the key concepts were highlighted, and the codes were extracted. After extracting the concepts and codes of the important sentences and paragraphs, they were grouped according to similarities and differences in the classes and the classes were combined based on their relationship with the main categories (15).

For accuracy, reliability and trustworthy of data, interviews and long meetings with participants were repeatedly performed. To revise peers, additional comments and suggestions from colleagues were used to verify and correct the accuracy of codes and categories, which were extracted. To review the participants, a number of interviews were also conducted after coding to determine consensus on codes between researchers and participants. It should be noted that this study was confirmed in terms of confidentiality and anonymity of the participants and ethical considerations were observed.

B) The quantitative step: it was performed based on a researcher-made questionnaire and after obtaining informed consent. Content validity of the questionnaire was confirmed by the feedback of experts and its reliability was assessed by the Cronbach's alpha 92\%. The number of students at this stage was 48 . The questionnaire had two parts; the first part included demographic information and the second part included the students' viewpoints regarding the resuscitation- training program. Some of the viewpoints were as follows: implementation of the resuscitation-training program improved my skills; I am satisfied with the resuscitation training program; I am in favor of continuing recovery in future semesters; the resuscitation training program was consistent with the needs of students,; and the quality of the training program was appropriate. These areas were ranked based on the Likert scale from strongly agree, agree, disagree, strongly disagree and disagree.

\subsection{Ethical Considerations}

The university's research ethics committee approved the study before the beginning of data collection. Students were informed of their right to withdraw participation at any time. 


\section{Results}

A) Results of the qualitative step: in the qualitative step, two students were married, two students were male and seven were female students. Their age range was between 21 and 23 years.

The results showed that the major category of promoting clinical skills was obtained with two classes of enhancing knowledge and specialized skill and obtaining qualification and becoming professional. The main category of attention to the educational needs was obtained with three categories of attention to the needs of students in clinical, reducing the theoretical training gap and increasing student satisfaction.

Promoting clinical skills: the category of promoting clinical skills consisted of two subcategories of enhancing knowledge and specialized skills, and obtaining qualification and becoming professional.

All students reported that the resuscitation- training program increased their knowledge and skills and by learning specialized programs, they felt that they were professionals. In this regard, a student said: “... Performing the newborn resuscitation program raised our knowledge of how to resuscitate as well as practical work like how to perform artificial respiration and heart massage..." (female student 4)

Another student stated that: "We knew something about adult resuscitation but the principles of newborn resuscitation is highly specialized and different from adults. By implementing this program, I feel we learned a specialized work" (male student 2)

The necessity of attention to the educational needs of students: the category of the necessity of educational needs of students was found with three categories of attention to the needs of students at clinical practice, reducing the practical training gap and increasing student satisfaction.

Most of the students stated that the resuscitationtraining program is one of the major educational needs of students and the need is felt in clinical practice. The students were more satisfied with the resuscitation-training program. In this regard, a student said:"... We are reading a lot of things that we have not applied in clinical practice, but the newborn resuscitation training is one of the important needs of the students in clinical practice..." (female student 6)

Another student said:"... One of the things that were beneficial for me was that the resuscitation-training program was taught in the form of theoretical and practical training and we were also given the opportunity to learn. It was so attractive to me that one day a group came to the Center for Clinical Skills to practice everything that we had learned, because we feel these are part of our work in the ward..."( female student 2)

Another student stated that:"... When I tried how to do endotracheal intubation for the baby on meconium, I feel happy that I managed to do a scientific work..." (male student 1)

“... Well, now I know what to do if a baby has apnea. I feel learned something special about resuscitation and feel good..." (female student 3 )

B) Results of the quantitative step: the number of students at this stage was 48 . In the quantitative step, five students were married and seven students were males. Their age range was between 21and 23 years. By analyzing the questionnaires, these data were obtained: The areas of the resuscitation-training program improved my skills (83\% strongly agree and $17 \%$ agree); I am satisfied with resuscitation-training program (6\% strongly agree, and $94 \%$ agree); I agree with continuing resuscitation in future terms (77\% strongly agree, $21 \%$ agree, and $2 \%$ disagree); the resuscitation training program was consistent with the needs of students (strongly agree 92\%, 4\% agree and $2 \%$ disagree); and the quality of the resuscitation training program was appropriate (94\% strongly agree and 6\% agree).

\section{Discussion}

Based on the results of the qualitative step, the major class of promoting clinical skills was obtained with two classes of enhancing knowledge and specialized skill and obtaining qualification and becoming professional. The main class of attention to the educational needs was obtained with three classes of attention to the needs of students in clinical, reducing the theoretical training gap and increasing student satisfaction. These results also confirmed by the results of the quantitative step.

The areas of the resuscitation-training program improved my skills (83\% strongly agree); I am satisfied with the resuscitation-training program ( $94 \%$ agree); I am in favor of continuing resuscitation in future terms (77\% strongly agree); the resuscitation-training program was consistent with the needs of students (92\% strongly agree); and the quality of resuscitation- training program was appropriate (94\% strongly agree). The results of other similar studies confirmed our findings. Findings of the Ergenekon et al. study showed that the resuscitation-training program on a mannequin can enhance newborn resuscitation performance (16). In addition, Yeung et al. in 2009 revealed that having skills in performing resuscitation depends on the knowledge and awareness in this area (17).

The results of Ruetzler et al. study in 2011 revealed that resuscitation training had a significant effect on im- 
proving students' knowledge and skills (18). The results of the Bismilla et al. study in 2010 showed that the resuscitation training on mannequins can enhance the performance of newborn resuscitation (19). Ahmady et al. stated that the successful recovery requires knowledge and skills (8). Sankar et al. in 2013 revealed that the resuscitationtraining program can increase students' knowledge and performance (20). Results of the Musafili et al. study revealed that despite increasing knowledge and skills of students after resuscitation training, training will help reestablish learning (21).

\subsection{Conclusions}

Considering that the nurses are the nearest associates of physicians and nursing students will serve in the health care system, performing the newborn resuscitation program in nursing students and increasing their knowledge and skills can lead to enhance student motivation, reduce hospital costs and improve the quality of health care services.

\section{Acknowledgments}

The authors are grateful to all the students in this study who were willing to share their experiences with us.

\section{References}

1. Kattwinkel J, Perlman JM, Aziz K, Colby C, Fairchild K, Gallagher J, et al. Part 15: neonatal resuscitation: 2010 American Heart Association Guidelines for Cardiopulmonary Resuscitation and Emergency Cardiovascular Care. Circulation. 2010;122(18 Suppl 3):S909-19. doi: 10.1161/CIRCULATIONAHA.110.971119. [PubMed: 20956231].

2. Rakshasbhuvankar AA, Patole SK. Benefits of simulation based training for neonatal resuscitation education: a systematic review. Resuscitation. 2014;85(10):1320-3. doi: 10.1016/j.resuscitation.2014.07.005. [PubMed: 25046744].

3. Lee AC, Cousens S, Wall SN, Niermeyer S, Darmstadt GL, Carlo WA, et al. Neonatal resuscitation and immediate newborn assessment and stimulation for the prevention of neonatal deaths: a systematic review, meta-analysis and Delphi estimation of mortality effect. BMC Public Health. 2011;11 Suppl 3:S12. doi: 10.1186/1471-2458-11-S3-S12. [PubMed: 21501429].

4. Bull A, Sweet L. Midwifery students receiving the newborn at birth: A pilot study of the impact of structured training in neonatal resuscitation. Nurse Educ Pract. 2015;15(5):387-92. doi: 10.1016/j.nepr.2015.03.002. [PubMed: 25851302].

5. Boskabadi H, Molaee MK, Ghavidel M. Determining the Viability of Preterm Newborns Hospitalized in the Neonatal Intensive Care Unit in Ghaem Hospital, Mashhad. J Mazandaran Univ Med Sci. 2014;24(119).
6. Singhal N, Lockyer J, Fidler H, Keenan W, Little G, Bucher S, et al. Helping Babies Breathe: global neonatal resuscitation program development and formative educational evaluation. Resuscitation. 2012;83(1):90-6. doi: 10.1016/j.resuscitation.2011.07.010. [PubMed: 21763669].

7. Dashti E, Rassouli M, Khanali Mojen L, Puorhoseingholi A, Shirinabady Farahani A, Sarvi F. Neonatal factors associated with preterm infants' readmissions to the neonatal intensive care units. J Hayat. 2015;21(3):29-40.

8. Ahmadi M, Nasiri E, Emadi SAA, Mohammadpour R. Assessment of knowledge attitude and practice of trainees on neonatal resuscitation in the healthcare center affiliated to the university of medical science of mazandaran. J Mazandaran Univ Med Sci. 2007;17:109-16.

9. Raghuveer TS, Cox AJ. Neonatal resuscitation: an update. Am Fam Physician. 2011;83(8):911-8. [PubMed: 21524031].

10. Woollard M, Whitfeild R, Smith A, Colquhoun M, Newcombe RG, Vetteer $\mathrm{N}$, et al. Skill acquisition and retention in automated external defibrillator (AED) use and CPR by lay responders: a prospective study. Resuscitation. 2004;60(1):17-28. [PubMed: 15002485].

11. Hensel D, Kathman J, Hendricks R, Ball S. Building partnerships using student role models for neonatal resuscitation simulation. J Contin Educ Nurs. 2012;43(12):550-4. doi: 10.3928/00220124-20120904-33. [PubMed: 22966772].

12. Aemmi SZ, Ahmadi Z, Reyhani T, Haghani H. Comparison of Perceptions of Nurses and Premature Infants' Mothers about Mothers' Needs in Neonatal Intensive Care Unit. J Hayat. 2013;19(2):14-26.

13. Creswell JW, Clark VLP. Designing and conducting mixed methods research. Wiley Online Library; 2007.

14. Hsieh HF, Shannon SE. Three approaches to qualitative content analysis. Qual Health Res. 2005;15(9):1277-88. doi: 10.1177/1049732305276687. [PubMed: 16204405].

15. Elo $\mathrm{S}$, Kyngas $\mathrm{H}$. The qualitative content analysis process. J Adv Nurs 2008;62(1):107-15. doi: 10.1111/j.1365-2648.2007.04569.x. [PubMed: 18352969].

16. Ergenekon E, Koc E, Atalay Y, Soysal S. Neonatal resuscitation course experience in Turkey. Resuscitation. 2000;45(3):225-7. [PubMed: 10959023]

17. Yeung J, Meeks R, Edelson D, Gao F, Soar J, Perkins GD. The use of CPR feedback/prompt devices during training and CPR performance: A systematic review. Resuscitation. 2009;80(7):743-51. doi: 10.1016/j.resuscitation.2009.04.012. [PubMed:19477574].

18. Ruetzler K, Gruber C, Nabecker S, Wohlfarth P, Priemayr A, Frass $M$, et al. Hands-off time during insertion of six airway devices during cardiopulmonary resuscitation: a randomised manikin trial. Resuscitation. 2011;82(8):1060-3. doi: 10.1016/j.resuscitation.2011.03.027. [PubMed: 21514986].

19. Bismilla Z, Finan E, McNamara PJ, LeBlanc V, Jefferies A, Whyte H. Failure of pediatric and neonatal trainees to meet Canadian Neonatal Resuscitation Program standards for neonatal intubation. J Perinatol. 2010;30(3):182-7. doi: 10.1038/jp.2009.152. [PubMed:19812585].

20. Sankar J, Vijayakanthi N, Sankar MJ, Dubey N. Knowledge and skill retention of in-service versus preservice nursing professionals following an informal training program in pediatric cardiopulmonary resuscitation: a repeated-measures quasiexperimental study. Biomed Res Int. 2013;2013:403415. doi: 10.1155/2013/403415. [PubMed: 23971033].

21. Musafili A, Essen B, Baribwira C, Rukundo A, Persson LA. Evaluating Helping Babies Breathe: training for healthcare workers at hospitals in Rwanda. Acta Paediatr. 2013;102(1):e34-8. doi: 10.1111/apa.12034. [PubMed: 23113836]. 